\section{Prophylaxis against venous thromboembolism}

EdroR,-We are disappointed that the review article on the risk of and prophylaxis against venous thromboembolism in hospital patients does not mention the advantageous effects of afferent blockade for patients undergoing surgical procedures.' The stress response to surgery increases angiotensin and catecholamine concentrations, which increase platelet aggregation. ${ }^{23}$ Hepatic synthesis of fibrinogen is increased, ${ }^{4}$ while synthesis of antithrombin III is reduced. ${ }^{5}$ Attenuated stress responses can be shown with epidural and spinal analgesia for lower abdominal and more distal surgery and with paravertebral analgesia for thoracic surgery (J Richardson et al, unpublished data). Proved benefits of afferent blockade include increased fibrinolytic activity ${ }^{\bar{\gamma}}$ and improved thromboelastography. ${ }^{8}$ In addition, lower limb blood flows are raised with epidural analgesia. ${ }^{9}$

These pathophysiological advantages are supported by an improvement in outcome after major surgery in patients managed with regional analgesia as well as, or instead of, general anaesthesia. Not only are venous thromboembolic events significantly $(p<0.05)$ reduced ${ }^{i 11}$ but other events related to coagulation are also favourably affected, including perioperative myocardial infarction ${ }^{\circ}$ and vascular graft patency. ${ }^{\circ}$

We do not take issue with the value of the mechanical and pharmacological methods described in the review, but the additional benefits offered by regional analgesia for surgical patients deserve emphasis.

JONATHAN RICHARDSON SABARATNAM SABANATHAN

Bradford Hospitals NHS Trust,

Anaesthetic Directorate,

Field House Postgraduate Centre,

Bradford Royal Infirmary,

Bradford BD9 6RJ

1 Thromboembolic Risk Factors (THRIFT) Consensus Group. Risk of and prophylaxis for venous thromboembolism in hospital patients. BMf 1992;305:567-74. (5 September.)

2 Ardle NG, Cameron HA, Garrett J. Platelet activation by circulating levels of hormones: a possible link in coronary circulating levels of hormones: a possib
heart disease. Thromb Res 1984;36:315-22.

3 Uza G, Crisnic I. Effects of angiotensin II upon platelet adhesiveness and the thromboelastogram in patients with essential arterial hypertension. Pathologia Europaea 1975;10: 327-32.

4 Weissman C. The metabolic response to stress: an overview and update. Anesthesiology 1990;73:308-27.

5 Flinn WR, McDaniel MD, Yao JST, Fahey VA, Green D. Antithrombin III deficiency as a reflection of dynamic protein metabolism in patients undergoing vascular reconstruction. I Vasc Surg 1984;1:888-95.

6 Kehlet $\mathrm{H}$. Surgical stress: the role of pain and analgesia. $\mathrm{Br} F$ Anaesth 1989;63:189-95.

7 Modig J, Borg T, Bragge L, Saldeen T. Role of extradural and of general anaesthesia in fibrinolysis and coagulation after total hip replacement. Br f Anaesth 1983;55:625-8.

8 Tuman KJ, McCarthy RJ, March RJ, Delaria GA, Patel RV, Ivankovich AD. Effects of epidural anesthesia and analgesia Ivankovich AD. Effects of epidural anesthesia and analgesia
on coagulation and outcome after major vascular surgery. on coagulation and outcome
Anesth Analg 1991;73:696-704.

9 Haljamae H, Frid I, Holm J, Akerstrom G. Epidural versus general anaesthesia and leg blood flow in patients with occlusive atherosclerotic disease. Eur f Vasc Surg 1988;2: 395-400.

10 Kehlet H. Effect of regional anaesthesia and pain management on surgical outcome. Practice in post-operative pain. Tunbridge Wells: Wells Medical, 1992.

11 Yeager MP, Glass DD, Neff RK, Brinck-Johnsen T. Epidural anesthesia and analgesia in high-risk surgical patients. Anesthesiology 1987;66:729-36.

EDIToR,- - The Thromboembolic Risk Factors (THRIFT) Consensus Group gives precise recommendations for preventing venous thrombosis. ' For medical patients the need for prophylaxis with low dose subcutaneous heparin is shown in those with acute stroke and myocardial infarction, but these results cannot be extended to the other groups of medical patients with moderate risk.

In this population-which represents most of our patients - the risk of venous thrombosis is low:
$9 \%$ for elderly medical inpatients ${ }^{2}$ and $4 \%$ for patients without cardiac or pulmonary diseases. In this large group of patients the benefit of prophylaxis has never been established by a randomised controlled trial (Halkin et al's study showing a reduction of mortality was an open, non-randomised trial $^{4}$ ). We recently participated in a double blind, controlled randomised study of 2474 elderly bedridden non-surgical inpatients that compared nadroparin $0.3 \mathrm{ml}$ and placebo. There was no significant difference between the low molecular weight heparin and the placebo in mortality $(10 \cdot 1 \%$ and $10.3 \%$ respectively) and overall incidence of thromboembolic events $(2.9 \%$ and $3.9 \%$ )

In medical patients without stroke or cardiopulmonary disease the risk of venous thrombosis is probably too low to be significantly reduced by heparin. There is no scientific reason for proposing systematic prophylaxis with low molecular weight or standard heparin in all these medical patients This costly recommendation has not been correctly evaluated.

JEAN-FRANCOOIS BERGMANN JEAN-MARC SEGRESTAA CHARLES CAULIN

Clinique Thérapeutique,

Hopital Lariboisier

Thromboembolic Risk Factors Consensus Group. Risk of and

prophylaxis for venous thromboembolism in hospital patients. prophylaxis for venous thromboembol
$B M 7$ 1 1992;305:567-74. (5 September.)

2 Dahan R, Houlbert D, Caulin C, Cuzin E, Viltart C, Woler M et al. Prevention of deep vein thrombosis in elderly medical in patients by a low molecular weight heparin. A randomized double-blind trial. Haemostasis 1986;16:159-64

Kierkegaard A, Norgren L, Olsson CG, Castenfors J, Persson G Persson S. Incidence of deep vein thrombosis in bedridden non-surgical patients. Acta Med Scand 1987;222:409-14.

4 Halkin H, Goldberg J, Modan M, Modan B. Reduction of mortality in general medical in-patients by low dose heparin prophylaxis. Ann Intern Med 1982;96:561-5.

AUTHOR'S REPLY,-Jonathan Richardson and Sabaratnam Sabanathan suggest that venous thromboembolism is less common after major surgery performed with regional anaesthesia compared with general anaesthesia. A recent critical review of comparative studies in hip surgery agreed that "there is good evidence that in patients who do not receive prophylaxis, the incidence of postoperative deep vein thrombosis is lower with regional anaesthesia than with general anaesthesia. However, the incidence is still substantial $(29-40 \%)$ in the unprotected patient and therefore regional anaesthesia should not be regarded as a substitute for effective primary antithrombotic prophylaxis. Whether the findings in unprotected patients can be extrapolated to patients who receive effective primary prophylaxis remains an open question which can only be answered by performing an appropriately designed randomized controlled trial."' We agree with this.

Jean-François Bergmann and colleagues question the use of prophylaxis in medical inpatients who do not have acute stroke, myocardial infarction, or other cardiopulmonary disease. We agree that these three groups make up most patients in acute medical wards in whom prophylaxis is indicated (in the United Kingdom they also make up most patients in acute medical wards). But other groups of patients immobilised in medical wards also merit prophylaxis-those with nonterminal malignancy, infections, inflammatory bowel disease, nephrotic syndrome, or paralysis of the lower limbs (for example, those with Guillain-Barré syndrome). Published work strongly suggests that these groups of patients have a significant risk of venous thromboembolism, and hence prophylaxis is rational.

Studies have consistently shown that prophylaxis with low dose heparin is effective in medical patients who do not have myocardial infarction or stroke. $^{2-5}$ The reduction in mortality in patients reated with heparin in the study of Halkin et al is consistent with such a reduction in the incidence of deep vein thrombosis and was observed in patients with infection or malignancy as well as in patients with cardiopulmonary diseases. ${ }^{6}$ We agree that this study used an unconventional, non-randomised method of allocating cases (even versus odd medical record numbers), but mortality was analysed by intention to treat (being recorded for all even numbered patients whether or not heparin was given), and hence significant bias is unlikely to have resulted."

We are interested to learn that the preliminary results of Bergmann and colleagues' study show a $26 \%$ reduction in thromboembolic events but no reduction in total mortality in the group treated with heparin. It is not clear whether patients with cardiopulmonary disease were included in this study: if they were not this may account for the different conclusion of their study from that of Halkin et $a l$, in which such patients were in the majority. ${ }^{\circ}$

Department of Medicine

University of Glasgow,

Royal Infirmary,

1 Prins $\mathrm{MH}$, Hirsh J. A comparison of general anesthesia and regional anesthesia as a risk factor for deep vein thrombosis following hip surgery: a critical review. Thromb Haemostas 1990;64:497-500

2 Gallus AS, Hirsh J, Tuttle RJ. Small subcutaneous doses of heparin in prevention of venous thrombosis. $N$ Engl $\mathcal{G ~ M e d}$ 1973;288:545-50.

3 Belch JJ, Lowe GDO, Ward AG, Forbes CD, Prentice CRM Prevention of deep vein thrombosis in medical patients by low-dose heparin. Scott Med f 1981;26:115-7.

4 Cade JF. High risk of the critically ill for venous thromboembolism. Crit Care Med 1982;10:448-50

5 Dahan R, Houlbert D, Caulin C, Cuzin E, Viltart C, Woler M, et al. Prevention of deep vein thrombosis in elderly medical in-patients by a low molecular weight heparin: a randomized double-blind trial. Haemostasis 1986;16:159-64.

6 Halkin H, Goldberg J, Modan M, Modan B. Reduction of mortality in general medical in-patients by low-dose heparin prophylaxis. Ann Intern Med 1982;96:561 -5.

\section{Needs of black and ethnic minorities}

EDITOR,-The analysis of the health needs of British ethnic minority groups presented in the 1991 report of the chief medical officer ${ }^{12}$ is well meaning but it oversimplifies complex issues, reinforces stereotypes, misses key new ideas, and presents misleading interpretations of data. The report's benefits to ethnic minority groups are likely to be outweighed by the stigma arising from the associated publicity. Let me substantiate these strong criticisms.

The report justifies the term black and ethnic minority because "it underlies a common experience of life in this country among people whose skin colour is not white" (my italics). Why then is the principal focus of the report on cultural and genetic factors, which vary at least as much between ethnic minority groups, as between them and the white community, when the common experience is one of family migration, the struggle for respect, wellbeing, and social position, a too ready alienation from white society, discrimination, and relative poverty? Black makes sense only in the social, not biological or cultural, context. Why is so little attention paid to heterogeneity within the ethnic minority groups when recent work has emphasised the problems created by inappropriate terminology that encourages a false impression of homogeneity, ${ }^{3}$ and has shown striking variation in socioeconomics, lifestyle, and disease patterns within even a Hindu community?+

The report is stereotyped for it reiterates established, much criticised, thinking. It also propagates the dangerous stereotype of ethnic minority groups being a problem. Without any notable 